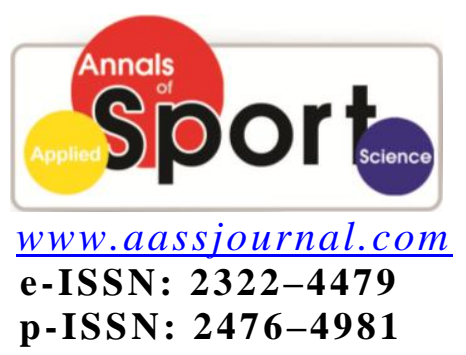

\title{
Driginal Article
}

Received: $17 / 06 / 2015$

Accepted: 25/08/2015

\section{Relationship between Game Location and Match Result with the Amount of Aggression: Iranian Premier League Football Teams}

\author{
${ }^{1}$ Farhad Alahvisi*, ${ }^{1}$ Mohammad Maleki, ${ }^{2}$ Farid Zand Salimi
}

1. Department of Physical Education and Sport Science, Kordestan University, Sanandaj, Iran.

2. Department of Physical Education and Sport Science, Sanandaj Branch, Islamic Azad University, Sanandaj, Iran.

\begin{abstract}
The purpose of this study was to investigate the relationship between game location (host advantage), match result (win, lose or tie) and the level of aggression in football teams of the Iranian Premier League. The study population consisted of Premier League Football teams (League XIII), and 60 matches (related to 4 teams) that were available for the researcher, were selected as the sample. The current study can be regarded as applied and descriptive, in terms of purpose and data collection, respectively. In order to collect data, the match videos of selected teams were studied, then the results of the observations were written and recorded using Roberts et al. (1999) aggression model. The results showed that no significant difference was found between teams' aggression in host and guest matches $(\mathrm{p}>0.05)$. But, a significant difference was observed between aggression and match result and the behaviors were more in lost matches $(\mathrm{p}<$ 0.05). In fact, mental stress caused by the loss resulted to more aggression to win. Hence, a match result, physical aggression and players' position led to significant difference in players' aggression. Therefore, the control and management of aggressive behaviors, especially at the time of failure will result in improved performance and efficiency of football teams. Also, these behaviors can be minimized by providing necessary training on anger management and negative emotions control among players.
\end{abstract}

Key Words: Host advantage, Win, Lose, Tie, Observation method.

Corresponding Author:

Farhad Allahvisi

E-mail: alahvisifarhad@gmail.com 


\section{INTRODUCTION}

In most countries of the world, football is played in a Premier League, where teams compete in matches as host and guest (1) . Game location is an important factor in the success of the exercise. The advantage of host matches in a lot of team and individual sports has been proven both at the professional and amateur levels (2) and a large number of studies have confirmed that athletes and teams which compete as the host, perform better (3-5) . Moris defined host advantage in football as the native reaction shown in response to the reaction of the players facing unusual conditions of an unfamiliar environment (6). In the literature, a host advantage is defined as: a case in which teams in back and forth (home and away) matches win more than 50 percent of their matches (7). The important factors affecting host advantage include: spectator support, trip works; familiarity with a game location, referee bias, native prejudice and psychological effects (6).

When athletes play as host or guest, they behave differently because of various reasons. For example, researchers have shown that coaches in most guest matches use a defensive approach and the instructions of the coach affect the behavior of the players (8). The results of most studies revealed that athletes show more effort and strength in host matches due to confidence boost (9). However, the results of many studies are contradictory on the relationship between athletes' aggression and game location. When aggressive behaviors of English Premier League teams were examined by indices of yellow card (carelessness), red card (exclusion), and penalty, a significant difference was found between aggressive behaviors of host and guest teams (10). The results of Howard also showed that athletes when they play as a host show more aggression (11). While the research by Jones indicated that no significant difference was found in aggression between host and guest matches in rugby (12). In another study, Rahnama et $a l$. by examining the number of yellow and red cards received by Premier League football teams in Iran came to the conclusion that no significant difference was found between the number of cards in host and guest matches (1). Thus, according to theoretical foundations and conducted studies, it seems that a game location can be an effective factor on the level of aggression in sports teams.

Among other variables that may play a role in the outbreak of football players' aggression is a game result (win, loss and tie). In football, it is normal to win or lose a match, but each can have different effects on player behavior. A correlation has also been observed in the relationship between players' aggression and game result. Studies have shown that winner teams were more aggressive on compared to teams that lost $(13,14)$. However, in other studies, the loser teams displayed more aggressive behaviors $(12,15,16)$. In order to justify aggression in lose situations; these studies used the failureaggression hypothesis. Different people under the same conditions may have a different sense of failure. In other words, different factors cause this feeling in people. A person's failure may be caused by lack of access to one's goals and desires, and in another person in spite of a team win, individual performance and mistakes may result in failure (16).

Aggression in sport is a multi-factor phenomenon that is connected with attack, failure, anger and functionality of environmental cues (17) and it leads to undesirable use of mental energy, which is an obstacle to game success and may distract the player from focusing by creating a mix of anger and excitement, thereby reducing players' performance (18). In some sports, a positive relationship is also found between 
aggressive behavior, anger control and successful implementation (17). Additionally, aggression raises a person's level of excitement and moves his attention toward non-performing results, such as thought of hurting an opponent (19); therefore, athletes' awareness of their behaviors, especially in contact sports, or when the board is important is valuable and decisive (17). Definitions of aggression in sport are a reflection of the definitions provided in psychology mainstream (20). Based on a comprehensive definition of Coakley, aggression is referred to as a behavior that is done with the intent to cause damage or harm to another person, and involves sheer disregard for the other's health, and possibly his. The consequences of aggression may be physical or psychological (21). Also, some consider aggression as an instinctive reaction to failure and competition for access to resources that are achieved mainly through physical contact (22). Aggression can be divided into hostile aggression and instrumental aggression and in terms of its tool can be divided into four namely verbal, physical, active and passive categories (23).

A review of the general research in recent years revealed aggression as one of the most important variables affecting team performance and enhanced efficiency. Also, according to the professionalization trend of football in the country, the aggressive behavior of players in the green rectangle is on the increase and may result in fighting, insult, profanity and many other controversial behaviors by players and coaches, sometimes beautiful scenes of football competitions can approach to ugliness by players, marred with violence and aggression. Although we cannot change the nature of a game, however there are certain measures by which many aggressive factors can be identified and minimized. Hence, according to the results of research and the theoretical foundations of the negative and destructive effects of aggression on the performance of athletes, especially in football, there is need for prevention, management and control of aggressive behaviors in players. The lack of research and lack of clear, accurate and scientific information in the field and given the importance of aggression issue and important psychological and behavioral consequences of aggression in the success trend of sports teams and athletic performance, had led to this research. Also, this research was necessitated by the conflicting reports of previous researches and the lack of a study that completely investigates the relationship between game location and match result with the level of aggression in Iran Premier League football. This study was conducted to investigate the relationship between game location, match result and the amount of aggression of Iran Premier League football players in the first half season of 2013-14. The study also investigated the psychological and behavioral effects of aggression and provided valuable solutions for improving team performance.

In general, the main hypotheses of this study are: A significant difference is found between aggression of football teams in host and guest matches, and also a significant difference is found between teams' aggression and a match result.

\section{MATERIALS AND METHODS}

The present study is an applied and descriptive survey in terms of the purpose and data collection, respectively.

Participants. The study population consisted of Iranian Premier League football teams (League XIII) in the 2013-2014 season, in 60 matches related to four teams in the first half of the season as the selected samples. Teams that failed to cooperate or could not provide the complete video of matches were eliminated, hence matches related to four teams that were willing to co- 
operate with the researcher were considered as the sample.

Tools. Data was collected in the form of a field, obtained through observation of the players and by recording observations of aggressive behavior. Roberts et al. designed a list of specific aggression types for use in their study where players' aggression was investigated, the list includes a space for inserting aggression type, players' profile, player position, time of onset of aggression, half of a match (first and second), being host or guest, team name, a previous match result and meeting date (24). Aggressive behaviors of the players were recorded in the list by modeling FIFA-12 item rule (mistakes and improper behaviors), which is based on physical and verbal aggression. To record the aggression list, a table was drawn for the event and the type of aggression by one of the players was determined based on FIFA 12-item rule. Then the profile of the player, the time of aggression display, match half session, the game location and match result were recorded in separate rows. In order to ensure the content and formal validity, first the list was examined by a few football coaches and physical education teachers with football expertise, and then it was reviewed and confirmed by conceptual and content modifications. Also, in order to ensure the accuracy of the data observed from match videos and earn more trust from the observations, inter- examiner and intraobserver reliability were measured. For this reason, some examples of match videos (20 percent of the whole matches) were given to one of the football coaches and a university student studying for his MA degree in physical education, to record their observations. The amount of correlation between the researcher and the football coach $(\mathrm{R}=0.91)$, as well as the amount of correlation between the researcher and MA university student $(\mathrm{R}=0.93)$, were obtained. In order to measure inter-observer reliability, a number of matches (20 percent of the whole matches) were observed within two weeks by the researcher again and the value of inter-observer correlation $(\mathrm{R}=0.95)$ was obtained. Using the host or guest variables, the level of aggression with respect to a match result were considered as independent variables and aggressive behavior of the players was considered as the dependent variable.

Procedure. Due to long analysis of video matches and the lack of access to complete video of Premier League matches, among the teams present in the Premier League, 60 matches related to four teams available to the researcher, were selected as study sample. In the current study, in order to observe the aggressive behaviors of the players, the videos of their matches were watched from a CD. The advantage of this in addition to accuracy is that this information is available to the researcher, and it can be studied and analyzed at any time without limitations. In addition, compared to the direct observation it enables the records of additional information. The study tool used for observation may not create any disturbance and as a result data collected was unbiased. The research examiners were three experienced persons to record aggressive behavior. All the examiners participated in a meeting and were enlightened on the study purposes, concepts of aggression, the identification method and how to record aggressive behavior in information record forms. In each match, two examiners were assigned to observe players' aggression and an examiner to record behaviors in the list.

Statistical Analysis. All data were extracted and set in a special table. Finally, the collected data were summarized and classified using descriptive statistics indices. The Kolmogorov-Smirnov test was used to determine the normality of data distribution. In the descriptive statistics, regarding abnormal data distribution, Mann-Whitney and Kruskal-Wallis tests were used to 
compare means. Also, data analysis was performed using the SPSS software at a significance level of 0.05 .

\section{RESULTS}

The average age of the players was 27.6 years. Among studied sample in different positions, $45.6 \%$ were halfback, $27.5 \%$ were defenders, $17.6 \%$ were strikers and $9.3 \%$ were goalkeepers.

The result of the current study showed that in a total of 60 studied matches, the teams showed 1793 aggressive behaviors. Also, mean aggression in each match was about 29.88 cases. The results of descriptive statistics are shown briefly in Table 1.

Table 1. Results of descriptive statistics

\begin{tabular}{ccccc}
\hline & \multicolumn{2}{c}{ Aggression } & \multicolumn{2}{c}{ a match half } \\
Statistical index & physical & verbal & first & second \\
\hline average & 19.62 & 10.26 & 15.58 & 14.30 \\
\hline sum & 1177 & 616 & 3 & 858 \\
\hline
\end{tabular}

As seen in Table 2, halfback players recorded an average of $16.06 \%$ of aggression in each match and displayed the most aggressive behavior. After halfback position, the defenders, strikers and goalkeepers displayed the maximum level of aggression, respectively.

Table 2. Players' aggression in different football positions

\begin{tabular}{ccccc}
\hline $\begin{array}{c}\text { behavior } \\
\text { Position }\end{array}$ & \multicolumn{3}{c}{ Physical and Verbal Aggression } \\
\cline { 2 - 5 } & striker & halfback & defender & Goalkeeper \\
Statistical index & & & & \\
\hline Total Aggression & 325 & 964 & 486 & 18 \\
\hline average & 5.41 & 16.06 & 8.1 & 0.3 \\
\hline
\end{tabular}

The results of Table 3 indicate that 4 teams selected during the half season were the host of 30 matches, hosting opposing teams and played in 30 matches on opponent ground. The results showed that no significant difference was found between the teams' aggression in both host and guest matches $(\mathrm{p}>0.05)$.

Table 3. The amount of teams' aggression in host and guest matches

\begin{tabular}{lcccc}
\hline & factors & number of matches & Mean \pm SD & $p$ \\
\hline \multirow{2}{*}{ Aggression } & host & 30 & $29.60 \pm 5.32$ & \multirow{2}{*}{0.97} \\
& guest & 30 & $30.17 \pm 6.52$ & \\
\hline
\end{tabular}

According to the results of Table 4, a significant difference at $\mathrm{p}<0.05$ was found between teams' aggression and lost matches. The Mann-Whitney $U$ test was used to compare pairs of groups. The results of the test showed that a significant difference is found between teams' aggression with lose and tie result, while no significant difference was observed between the teams' aggression with tie and win result $(\mathrm{p}<0.05)$. 
Table 4. The amount of teams' aggression according to a match result

\begin{tabular}{cccc}
\hline Match result & The number of matches & Mean \pm SD & p \\
\hline win & 20 & $26.65 \pm 3.4$ & \\
lose & 19 & $34.84 \pm 5.12$ & 0.001 \\
tie & 21 & $28.48 \pm 5.7$ & \\
\hline
\end{tabular}

\section{DISCUSSION}

This research was conducted to examine the level of aggressive behavior in Iranian Premier League Football teams, in the first half season of 2013-14. The findings of the present study showed that no significant difference was found between teams' aggression in host and guest matches. This was consistent with the findings of (12) and (1). They found that no significant difference was found between the aggression pattern in host and guest matches; though these results are inconsistent with the findings of (10) and (11). This indicates that Iranian Premier League teams in host and guest matches have almost identical aggression patterns. So, it seems that game location had no significant effect on the incidence of aggression on Iranian Premier League Football teams.

A significant difference was found between teams' aggression with respect to a match result, but the aggressive behaviors were higher in lost matches. The findings are consistent with the results of (12), (15) and (16). The fact is that mental stress caused by the loss has led to more aggression to win and tie position. The results of the hypothesis can be explained based on the failure-aggression theory (25). Although players' response to failure is different, as a result of the broad scope of failing factors and players' characters, but in sports, failure is often a result of an unsuccessful event or result. In fact, failure is a barrier to achieving the specific goals and demands of an individual and inevitably is expressed in an aggressive behavior. When a person fails to achieve his goals and desires, he may show more aggressive behaviors; thus, it seems that in a severe competition, such as football, failure will lead to more aggressive behaviors and diversity. As the losing teams are more prone to aggressive behavior (15).

Among other results of the present study, is that a significant difference in players' aggression in different positions was noted. The results revealed that halfback position players displayed the most aggressive behavior pattern. Regarding ball circulation time and the high density of players in the mid-field during a football match, it is expected that halfback position players would display more aggression (26). Also, a significant difference was found between physical and verbal aggression. Given that football is a tension match and players fight for the ball physically, it is expected to witness more of physical than verbal fighting. This result (26) is inconsistent with the findings. Their results showed that no significant difference was found between physical and verbal aggression. Possibly the reason for the inconsistent results is the number of teams that were selected for the study. In their study, a team was examined only in host matches, while the present study was conducted with more teams both in host and guest matches.

Additionally, no significant difference was observed between teams' aggression in the first and second halves. This result is consistent with (16) and (26). Their result showed that no significant difference was found between the level of players' aggression in the first and second halves of football games; and between aggressive behaviors in basketball game quarters. Therefore, in Premier League teams in each 
of the two halves of a match, there is the possibility of aggression outbreak.

Overall, it can be concluded that various factors such as a match result, players' position, the level of physical contact, failure, etc. may play a role in aggression outbreak. According to the results of the current study, we can say that a match result, physical aggression and players' position contributed to players' aggression; given the important role of halfback position players in attack and defense, it is common for fighting to occur in that area of the field, coaches should reduce the ground for outbreak of aggressive behaviors by controlling and conducting the behavior of players. Also, according to failure hypothesis and since failure caused most of the teams' aggression, the players should learn to tolerate loss and be prepared mentally for a game. Preparation of athletes is the responsibility of team coaches and psychologists. Also, although failure is difficult and its tolerance is unpleasant, players should learn that they cannot always win under different conditions, and should be able to accept defeat when they lose. Additionally, team coaches and psychologists should be familiar with players' reaction, especially during failure and understand their behaviors, identify players' weaknesses and attempt to change and modify these behaviors.

\section{CONCLUSION}

Finally, it should be noted that although, the possibility of showing aggressive and violent behavior in football is high because of a competitive environment and failure factors, these behaviors can be reduced significantly by providing necessary training for anger and control of negative emotions among players. Also, given that the sensitivity and mental stress of a match stimulates players for further aggressive behaviors, it is therefore recommended to use appropriate measures to manage the behavior and control the players' negative emotions, because controlling these behaviors can enhance the performance and efficiency of the players. Finally, it should be noted that this research was conducted using a limited study sample of four football teams of the Iranian Premier League. One of the limitations of this study is the lack of access to the complete videos of the matches; therefore, generalization of the results should be done carefully. To draw definite conclusions, more studies have to be conducted on Iranian Premier League football teams. Therefore, since the current study was conducted with only four teams, it is recommended that future studies should be conducted with a larger number of samples and in other fields of sports. Also, it is recommended to study the level of these behaviors in a match, in order to examine the level of aggression with a match result.

\section{APPLICABLE REMARKS}

- It is necessary that the coaches control and manage the behaviors and negative excitements of athletes especially in failure, and with avoiding from problems, putting up the moral and cultural principles of the team on priority of their programming.

- Coaches and sports psychologists can identify aggressive players, and control their behavior with special programs and considerations. 


\section{REFFRENCES}

1. Rahnama N, Sadeghipour HR, Bambaeichi E. Comparison Of Iranian Football Professional Performance At Home And Away Games. Olympic. 2007;14(4):39-45 [Article in Farsi].

2. Pollard R, Pollard G. Long-term trends in home advantage in professional team sports in North America and England (1876-2003). J Sports Sci. 2005;23(4):337-50.

3. Allen MS, Jones MV. The "Home Advantage" in Athletic Competitions. Current Directions in Psychological Science. 2014;23(1):48-53.

4. Armatas V, Pollard R. Home advantage in Greek football. European journal of sport science. 2014;14(2):116-22.

5. Jones MB. The home advantage in individual sports: An augmented review. Psychology of Sport and Exercise. 2013;14(3):397-404.

6. Smith DR. Disconnects between popular discourse and home advantage research: what can fans and media tell us about the home advantage phenomenon? J Sports Sci. 2005;23(4):351-64.

7. Courneya KS, Carron AV. The home advantage in sport competitions: a literature review. Journal of Sport \& Exercise Psychology. 1992;14(1):13-27.

8. Dennis PW, Carron AV. Strategic decisions of ice hockey coaches as a function of game location. J Sports Sci. 1999;17(4):263-8.

9. Bray SR, Martin KA. The effect of competition location on individual athlete performance and psychological states. Psychology of Sport and Exercise. 2003;4(2):117-23.

10. Thomas S, Reeves C, Smith A. English soccer teams' aggressive behavior when playing away from home. Perceptual and motor skills. 2006;102(2):317-20.

11. Howard DA. The Effect of Aggression and Performance on Home Field Advantage. Scholarly and Creative Works Conference; The Dominican University of California2015.

12. Jones MV, Bray SR, Olivier S. Game location and aggression in rugby league. J Sports Sci. 2005;23(4):387-93.

13. Widmeyer WN, Birch JS. Aggression in professional ice hockey: a strategy for success or a reaction to failure? The Journal of psychology. 1984;117(1st Half):77-84.

14. Worrell GL, Harris DV. The relationship of perceived and observed aggression of ice hockey players. International Journal of Sport Psychology. 1986;17(1):34-40.

15. Scholtz G, Willemse J. Antecedents of aggression in sport. Journal for Research in Sport, Physical Education and Recreation. 1991;14(1):51-62.

16. Vaez Mousavi SMK, Shojai M, Samandar G. An Associntion Between Coache Behaviors Aggressive And Assertive Actions And Players. Harakat. 2004(20):5-22 [Article in Farsi].

17. Vaez Mousavi SMK, Mosayebi F. Sport Psychology. 1st ed. Tehran, Iran: SAMT Publication; 2012 [Book in Farsi]. $350 \mathrm{p}$.

18. Talaei R, Hossein pour M. Aggression between student athletes. Growth in Physical Education Teaching. 2012;4(3):54-2 [Article in Farsi].

19. Weinberg RS, Gould D. Foundations of Sport and Exercise Psychology, 6E: Human Kinetics Publishers; 2014. $664 \mathrm{p}$.

20. Grange P, Kerr JH. Physical aggression in Australian football: A qualitative study of elite athletes. Psychology of Sport and Exercise. 2010;11(1):36-43.

21. Coakley JJ. Sport in society: issues \& controversies: McGraw-Hill Inc.; 1997.

22. Argyle M. Bodily Communication: Taylor \& Francis; 2013. 384 p.

23. Buss AH, Perry M. The Aggression Questionnaire. Journal of Personality and Social Psychology. 1992;63(3):452-9.

24. Roberts GC, Spink KS, Pemberton CL. Learning Experiences in Sport Psychology: Human Kinetics; 1999. 191 p.

25. Dollard J, Miller NE, Doob LW, Mowrer OH, Sears RR. Frustration and aggression. New Haven, CT, US: Yale University Press; 1939. viii, 213 p.

26. Ramazani R, Rahmani Nia F, Boroumand MR. The Study of Disclosure of Aggressive Behaviors among "Pegah Club" Soccer Players in Professional League Competitions in Iran. Journal of Sport Management. 2009;1(1):10117 [Article in Farsi]. 
تازههاى علوم كاربردى ورزش

مقاله اصيل

دوره سوم، شماره جهارم

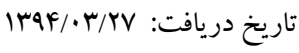

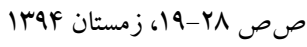

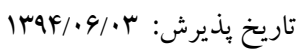

\section{رابطهى بين مكان مسابقه و نتيجهى بازى با ميزان يرخاشًَرى در تيمهاى ليخَ برتر فوتبال ايران 'فرهاد الهويسى *؛ مُحمد ملكى، "فريد زند سليمى}

ا. كارشناس ارشد تربيت بدنى، كروه تربيت بدنى و علوم ورزشى، دانشخاه كردستان، سنندج، ايران.

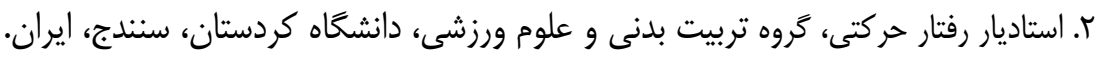

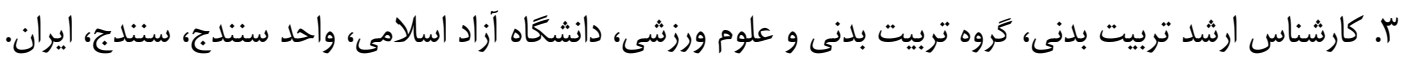

جكيده

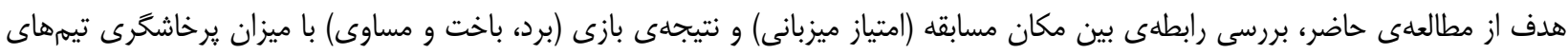

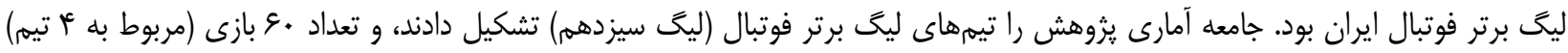

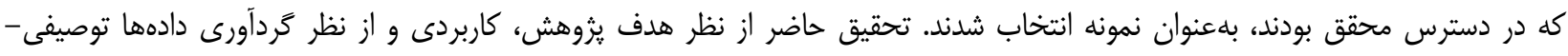

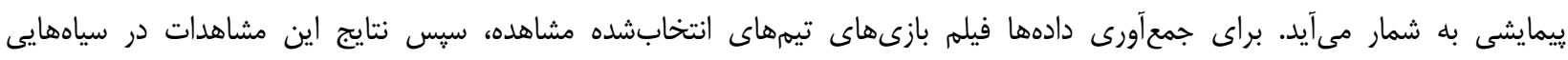

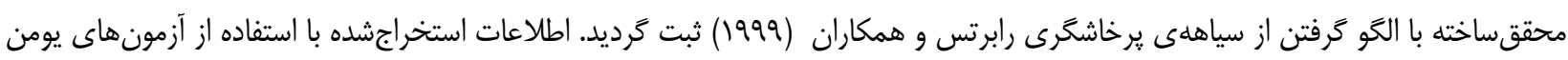

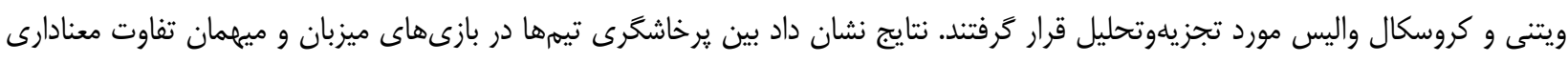

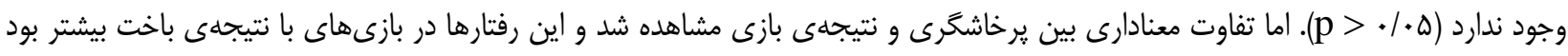

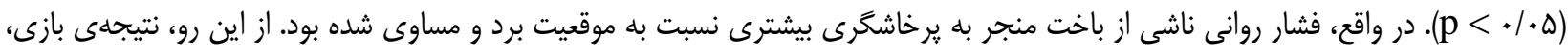

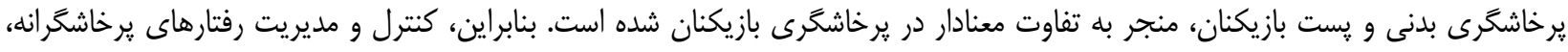

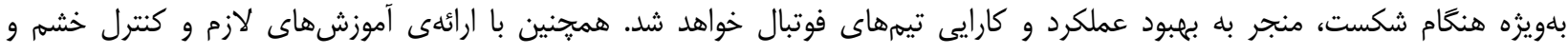

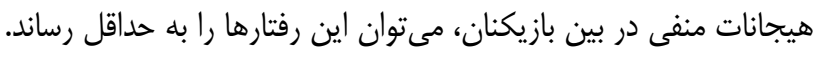
وازَّان كليدى: امتياز ميزبانى، برد، باخت، مساوى، روش مشاهدها

فر " - نوسنده مسئول:

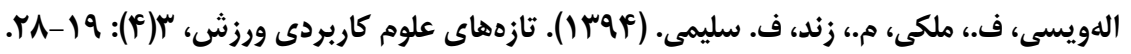


